\title{
OS LIMITES DA FORMAÇÃO DOCENTE E A EDUCAÇÃO DAS PESSOAS COM DEFICIÊNCIA NAS LICENCIATURAS
}

\author{
Maria Cristina Dancham Simões (Universidade Paulista)* \\ Carlos Antônio Giovinazzo Junior (PUC/SP)**
}

\begin{abstract}
RESUMO
O artigo trata da formação de professores para a educação de alunos com deficiência na escola básica brasileira. Problematizou-se a formação inicial e a temática focalizada, recorrendo-se aos dados coletados em pesquisa sobre as disciplinas e projetos pedagógicos de cursos de licenciatura de universidades federais. Identificouse a ausência de conteúdo político da educação escolar, da prática pedagógica e da formação docente, o que se expressa no modo como as licenciaturas tratam a educação das pessoas com deficiência. Recorreu-se às Diretrizes Curriculares Nacionais para a Formação Inicial e Continuada dos Profissionais do Magistério da Educação Básica para criticar as políticas educacionais e sustentar que os cursos de licenciatura não possibilitam aos seus alunos o aprofundamento teórico sobre a educação inclusiva e os problemas enfrentados na escola. Tais diretrizes reafirmam a função docente pautada na valorização da técnica como fim em si mesma e, por isso, como técnica de adaptação e controle social. A argumentação parte de uma perspectiva crítica a respeito da educação, baseada nos escritos de T. W. Adorno e no conceito de formação do indivíduo.
\end{abstract}

Palavras-chave: Formação docente. Educação inclusiva. Políticas educacionais.

\begin{abstract}
THE LIMITS OF TEACHER FORMATION AND THE EDUCATION OF PEOPLE WITH DISABILITIES

The article analyzes the training of teachers for the education of students with disabilities in the Brazilian basic school. The initial teacher training and the education of these students were examined from research on the disciplines and pedagogical projects of courses promoted by federal universities. It was identified the absence of political content of school education, pedagogical practice and teacher training, which is expressed in the way that the courses for the habilitation of teachers take care of the education of people with disabilities. The National Curricular Guidelines for the Initial and Continuing Education of Professionals of the Magisterium of Basic Education were used to criticize the educational policies and to maintain that the initial teacher
\end{abstract}

\footnotetext{
* Doutora em Educação pela Pontifícia Universidade Católica de São Paulo (PUC/SP). Professora Titular do curso de Psicologia da Universidade Paulista (UNIP). E-mail: macris.simoes@gmail.com

** Doutor em Educação pela Pontifícia Universidade Católica de São Paulo (PUC/SP). Professor da disciplina do Programa de Pós-Graduação em Educação - Educação: História, Política e Sociedade (PPGE/PUC/SP). Membro do grupo de pesquisa Diretório CNPq - Teoria crítica, formação e cultura (PUC/SP). E-mail: cgiovinazzo@pucsp.br
} 
formation courses do not allow their students the theoretical and critical study of inclusive education and the problems present in the school. These guidelines define the teaching function based on the valorization of the technique as an end in itself and, therefore, as a technique for the adaptation and the exercise of social control. The argumentation is oriented in a critical perspective of the education, based on the writings of T. W. Adorno and the concept of formation of the individual.

Keywords: Teacher education. Inclusive education. Educational policies.

\section{RESUMEN}

\section{LOS LÍMITES DE LA FORMACIÓN DOCENTE Y LA EDUCACIÓN DE LAS PERSONAS CON DISCAPACIDAD}

El artículo trata de la formación de profesores para la educación de alumnos con discapacidad en la escuela básica brasileña. Se analizó la formación inicial docente y la educación de esos alumnos recurriendo a la investigación sobre las disciplinas y proyectos pedagógicos de cursos de licenciatura promovidos por las universidades federales. Se identificó la ausencia de contenido político de la educación escolar, de la práctica pedagógica y de la formación docente, lo que se expresa en el modo en que las licenciaturas tratan la educación de las personas con discapacidad. Se recurrió a las Directrices Curriculares Nacionales para la Formación Inicial y Continuada de los Profesionales del Magisterio de la Educación Básica para criticar las políticas educativas y aseverar que los cursos no posibilitan a sus alumnos el estudio teórico y crítico de la educación inclusiva y los problemas enfrentados en la escuela. Tales directrices reafirman la función docente pautada en la valorización de la técnica como fin en sí mismo y, por eso, como técnica para la adaptación y el control social. La argumentación parte de una perspectiva crítica acerca de la educación, basada en los escritos de T. W. Adorno y en el concepto de formación del individuo.

Palabras clave: Formación de profesores. Educación inclusiva. Políticas educativas.

\section{Introdução}

Desde o final do século passado, inúmeras iniciativas foram realizadas com o objetivo de promover condições para que a educação escolar no Brasil ganhasse em organização e racionalidade. Boa parte dos envolvidos nas ações políticas tem como principal preocupação a melhoria da qualidade do trabalho educativo realizado com crianças, adolescentes e jovens (e adultos) das mais variadas origens e condições sociais, o que em tese contemplaria a diversidade cultural brasileira. Tal intento somente seria alcançado se as escolas obedecessem a certos princípios e fundamentos definidos nacionalmente e se possuíssem condições objetivas (autonomia administrativa, recursos financeiros, apoio para desenvolver infraestrutura etc.).

No que diz respeito ao sistema de ensino, é possível identificar a criação e a consolidação de alguns dispositivos políticos e financeiros que contribuem para que as redes de escolas (municipais, estaduais e federal) possam ser estruturadas e organizadas com base em diretrizes que cobrem todo o território nacional. São os casos do Fundo de Manutenção e Desenvolvimento da Educação Básica e de Valorização dos Profissionais da Educação (Fundeb), do Sistema de Avaliação da Educação Básica (SAEB), da Lei de Diretrizes e Bases da Educação Nacional (LDBEN), dos Parâmetros Curriculares Nacionais (PCNs) e das diretrizes curriculares estabelecidas para cada disciplina escolar e para os vários níveis da educação básica (educação infantil, ensino fundamental e ensino médio). Tudo isso se inscreve na conjuntura das reformas educacionais promovidas em vários países, incluindo o Brasil, e relacionadas com o fortalecimento do chamado neoliberalismo 
como ideologia da reestruturação produtiva ocorrida no âmago do capitalismo avançado. ${ }^{1}$

Temos também as Diretrizes Curriculares Nacionais para a Educação Profissional de Nível Médio, as Diretrizes Operacionais para a Educação Básica nas Escolas do Campo, as Diretrizes Curriculares Nacionais para a Educação das Relações Étnico-Raciais e para o Ensino de História e Cultura Afro-Brasileira e Africana, as Diretrizes Operacionais para o Atendimento Especializado na Educação Básica, modalidade Educação Especial, as Diretrizes Operacionais para a oferta de Educação de Jovens e Adultos, as Diretrizes Nacionais para a oferta de educação para jovens e adultos em situação de privação de liberdade nos estabelecimentos penais, as Diretrizes para o atendimento de educação escolar de crianças, adolescentes e jovens em situação de itinerância, as Diretrizes Curriculares Nacionais para a Educação Escolar Quilombola, as Diretrizes Curriculares Nacionais para a Educação Escolar Indígena na Educação Básica, as Diretrizes Nacionais para a Educação em Direitos Humanos e as Diretrizes Curriculares Nacionais para a Educação Ambiental. Todos esses dispositivos legais foram elaborados tendo em vista direcionar a educação básica e suas políticas para a perspectiva da diversidade cultural brasileira, dos direitos humanos e da inclusão social daqueles que, por sua origem ou condição, são excluídos do exercício da cidadania, marginalizados ou segregados (BRASIL, 2015, p. 9).

A menção a essa extensa lista é feita apenas para assinalar a complexidade com que a prática pedagógica é tratada. As situações nas quais as escolas estão inseridas, os problemas e dificuldades que os professores necessitam enfrentar no seu cotidiano e o reconhecimento de que a escola deve acomodar diferentes públicos, respeitando suas especificidades e condições, passaram a fazer parte do debate em torno das políticas educacionais. Sem dúvida, isso expressa o avanço no tratamento dado às questões de ordem social e cultural e da democracia. No entanto, também revela o quão fragmentado está o campo educacional, com grupos e movimentos buscando garantir que seus interes-

1 Para uma análise desse processo, recomenda-se a consulta aos seguintes autores: Sader e Gentili (1995); Freitas (2004); Moraes (2002); Stromquist (2012); Santomé (2003). ses sejam contemplados em uma conjuntura que dificulta a unificação da luta social e impõe ações que prioritariamente objetivem a participação nas relações assimétricas de poder.

Isso também pode ser observado no caso da formação de professores para a educação básica e das pessoas com deficiência. Tome-se o Parecer $\mathrm{CNE} / \mathrm{CP} \mathrm{n}^{\mathrm{o}} 2$, de 09 de junho de 2015, que apresenta as Diretrizes Curriculares Nacionais para a Formação Inicial e Continuada dos Profissionais do Magistério da Educação Básica (BRASIL, 2015). Considera-se que esse documento apresenta variados aspectos merecedores de exame mais minucioso, pois uma leitura rápida pode dar a entender que o fato de uma multiplicidade de situações ser abrangida, exprimindo certa concepção mais ampliada sobre a docência, denota que os problemas enfrentados por professores formadores, estudantes e instituições de ensino superior, observadas até então, foram dirimidos. O que se pretende demonstrar é que, mesmo sem que esteja explícito, prevalece uma situação em que é priorizada a formação que hipoteticamente valoriza a técnica em detrimento de uma proposta que pudesse articular educação, formação docente e política, já que nada é formulado em termos de fazer com que os cursos de licenciatura ganhem em consistência teórica.

Em outros termos: a técnica não é compreendida como um conjunto articulado de conhecimentos sobre processos, métodos e procedimentos acerca de um ofício, conferindo habilidade para realizar determinadas atividades. Tampouco é definida em oposição à teoria, já que não há proposta educacional na qual não seja assinalada a necessidade de junção entre esta e a prática. A técnica é concebida como fim em si mesma: no lugar de tomá-la como meio tendo em vista objetivos, ela é transformada na própria finalidade - e a teoria é valorizada apenas na medida em que ilumina a prática. Desse modo, a educação das pessoas com deficiência, sendo uma oportunidade para o enriquecimento da experiência coletiva, poderia proporcionar ao professor condições para a reflexão sobre as alternativas históricas, o que, por sua vez, poderia pôr em evidência as possibilidades de transformar a própria educação em geral e a escola. Contudo, não é o que acontece. A preocupação prioritária é a apropriação de técni- 
cas que tornem viável a resolução dos problemas enfrentados pelo professor com alunos deficientes.

\section{Os cursos de licenciatura e a educação de pessoas com deficiência}

Para ilustrar a perspectiva adotada, recorre-se à pesquisa de Simões (2016), que visou compreender de forma ampla as propostas de formação de professores para a educação básica, particularmente no que diz respeito à educação de pessoas com deficiência. Na referida pesquisa, foi realizado estudo latitudinal a partir dos projetos pedagógicos de cursos (PPC) de licenciatura, especificamente da formação inicial de professores dos anos finais da educação básica, de universidades federais de todas as regiões do país. ${ }^{2}$ Analisou-se o conteúdo das disciplinas que faziam referência à temática $\mathrm{e}$ uma amostra dos projetos que as abarcava, considerando as características do curso, justificativas, objetivos, competências a serem trabalhadas e o perfil do egresso.

\section{Sobre as disciplinas}

É possível afirmar que existe pouco mais de uma disciplina por curso (1,55 disciplina em média) que faça referência à temática, ofertada em por volta de 60 horas e de forma obrigatória na maioria dos cursos e predominantemente entre o $6^{\circ}$ e $8^{\circ}$ semestres. ${ }^{3}$ Cabe destacar, conforme Simões (2016) indicou, que a disciplina majoritariamente oferecida é a referente ao ensino da Língua Brasileira de Sinais (Libras), obrigatória por força de lei específica. Muitos PPC indicam explicitamente a Lei $\mathrm{n}^{\circ} 10.436$, de 2002, para reforçar a obrigatoriedade da existência

2 Com base nos Parâmetros Curriculares Nacionais para o Ensino Médio, elegeu-se os cursos de universidades federais de maior tamanho e tempo de existência, a fim de buscar informações relativas aos títulos, conteúdos programáticos, objetivos e referências das disciplinas destinadas (ou que faziam menção) às temáticas da educação de pessoas com deficiência.

3 Como resultado da coleta de dados, foram encontradas 550 disciplinas entre 13 cursos de 27 universidades federais. Por conta da variedade e complexidade do material coletado, Simões (2016) realizou seleções e filtragens variadas, com base nos títulos, nas ementas e nas disciplinas que se repetiam. Tratamentos diferentes foram realizados a partir de tais seleções, porém aqui é destacado aquele que teve como referência as ementas e conteúdos programáticos, a partir do qual se encontrou 434 disciplinas. da disciplina, porém, ao mesmo tempo, transparece certa dificuldade ou tensão, uma vez que há de se considerar que toda a estrutura de um curso, qualquer que seja ele, advém da obrigatoriedade imposta por regulamentações legais. A explicitação da imposição de uma lei específica, e não de todas as que regulam igualmente o documento, é expressão dessa tensão. Cabe destacar também que a lei da obrigatoriedade do ensino de Libras foi criada para regulamentar o artigo 18 da Lei n ${ }^{\circ} 10.098$, de 2000, que trata da necessidade de criação de condições para lidar na escola com as pessoas que apresentam as mais variadas deficiências, porém ocorreu apenas a regulamentação sobre a deficiência auditiva, desconsiderando-se até o momento, as demais, que possuem necessidades específicas e diversas. Finalmente, conforme indicado por Simões (2016), o conteúdo programático das disciplinas encontradas não indica a preocupação com as especificidades do curso em que se insere a disciplina de Libras.

De qualquer maneira, a sistematização dos dados permitiu um conjunto de indagações e problematizações acerca da formação docente para as temáticas da deficiência. Considerando a já referida amplitude e variedade, bem como as repetições de disciplinas entre cursos de uma mesma universidade, é apresentada uma análise aprofundada do conteúdo coletado, que relaciona a quantidade de disciplinas levantadas (434 disciplinas, com ementa e conteúdo passíveis de análise) com a qualidade de seu conteúdo.

No tocante ao conteúdo das disciplinas encontradas, foi possível identificar cinco eixos de análise (que exprimem a abrangência dos conteúdos apresentados nas disciplinas) referentes a expressões e frases encontradas no material coletado: 1) Sociedade, história e cultura, que contemplavam a indicação do entendimento feito das relações sociais em geral; 2) Conceituações, que abarcavam explicitação de conceitos, termos, nomenclaturas e definições; 3) Legislações e políticas, que agregavam as referências à legislação passada ou vigente, bem como políticas educacionais ou de inclusão; 4) Práticas de inclusão, composta por referências à inclusão de pessoas com deficiência, sem menção a aspectos pedagógicos, pois, nesse caso, são abarcadas no próximo eixo; 5) Questões pedagógicas. Esses eixos permitiram examinar a abrangência e 
a profundidade com as quais as temáticas da educação das pessoas com deficiência são trabalhadas nas licenciaturas.

A relação entre a quantidade de disciplinas que se repetiam e os desdobramentos dessas repetições permitiu o questionamento acerca da função e da contribuição efetiva de tais disciplinas à formação profissional docente. Nas análises, no que diz respeito à abrangência, foram identificadas duas configurações: em alguns casos, as disciplinas que se repetiam nas licenciaturas abrangiam todos ou quase todos os cursos de uma mesma universidade, enquanto em outras instituições as disciplinas não se repetiam, porém seu conteúdo era mais restrito, com quantidade menor de eixos identificados nos seus planos de aula e ementas. Questiona-se quais dessas duas configurações, considerando as possibilidades de resistência ao mundo administrado do capitalismo avançado e à heteronomia, poderia oferecer maior possibilidade de formação política, cultural e prática aos alunos dos cursos de licenciatura. Outros estudos aprofundados poderiam ser levados a cabo para dar conta dessa observação e se constituírem referências para a organização do conteúdo teórico e para as experiências práticas oferecidas nas universidades.

Tomando-se os cinco eixos de análise, apresenta-se a Tabela 1 com o número das disciplinas coletadas, considerando o valor absoluto (com repetições - ofertadas para alunos de dois ou mais cursos) e as entradas únicas (sem repetições ofertada para alunos de apenas um curso), para explorar a abrangência da temática da educação de pessoas com deficiência nas disciplinas (em que a quantidade (f1) permite inferir quanto à incidência dos eixos), a distribuição dos cursos por esses mesmos eixos e, por consequência, o número de alunos que as cursam, enquanto a qualidade (f2) permite observar os eixos abrangidos e estudados nas disciplinas, bem como o conteúdo apresentado aos futuros professores.

Tabela 1 - Distribuição dos temas/eixos das disciplinas relacionadas à educação de pessoas com deficiência, com (f1) e sem (f2) repetição das duplicadas

\begin{tabular}{|c|c|c|c|c|c|c|c|}
\hline $\begin{array}{l}\text { Tema/eixos } \\
\text { (abrangência da disciplina) }\end{array}$ & & $\mathbf{f 1}$ & $\%$ & & f2 & $\%$ & $\begin{array}{c}\neq \\
(2)\end{array}$ \\
\hline Sociedade, história e cultura & $4^{\circ}(1)$ & 195 & 18,1 & $3^{\circ}$ & 91 & 20,2 & 104 \\
\hline Conceituação & $3^{\circ}(1)$ & 215 & 20,0 & $4^{\mathrm{o}}$ & 85 & 18,8 & 130 \\
\hline Legislação e Políticas & $5^{\circ}(1)$ & 139 & 12,9 & $5^{\circ}$ & 45 & 10,0 & 94 \\
\hline Práticas de Inclusão & $1^{\circ}(1)$ & 267 & 24,8 & $2^{o}$ & 96 & 21,3 & 171 \\
\hline Questões Pedagógicas & $2^{\circ}(1)$ & 259 & 24,1 & $1^{\mathrm{o}}$ & 134 & 29,7 & 125 \\
\hline Total & & 1075 & 100,0 & & 451 & 100,0 & 624 \\
\hline
\end{tabular}

(1) Referem-se à ordenação de acordo com a frequência (da maior para a menor) dos eixos nas disciplinas examinadas.

(2) Refere-se à diferença entre $\mathrm{f} 1 \mathrm{e} \mathrm{f} 2$.

Fonte: Simões (2016, p. 100).

Na relação entre quantidade (f1) e qualidade (f2), é possível identificar que o eixo "Legislação e Políticas" abriga o menor número de referências nas disciplinas analisadas, enquanto que os demais eixos intercambiam suas posições. "Sociedade, História e Cultura" e "Questões Pedagógicas" têm sua incidência relativa aumentada ao se considerar a qualidade do conteúdo (f2) - o que pode ser analisado a partir das porcentagens de f1 e f2, bem como pelos números ordinais indicados à esquerda, na tabela. "Conceituação" e "Práticas de Inclusão", por sua vez, têm a incidência diminuída, 
quando consideradas as disciplinas sem repetição (f2). Sobre isso, inferências abrem o campo para pesquisas futuras, no sentido de verificar a viabilidade da seguinte afirmação: nas licenciaturas são priorizados conteúdos que forneçam uma espécie de visão geral sobre a educação de pessoas com deficiência e sobre as deficiências, e, também, sobre aspectos que introduzem os futuros professores nas questões educacionais concernentes à educação especial e à educação inclusiva; conceitos, definições e o processo de inclusão parecem ganhar menos visibilidade nas disciplinas analisadas. Em outros termos, a tendência observada é a de que as disciplinas que tratam da educação das pessoas com deficiência sejam aquelas específicas de cada curso, sem aquelas ofertadas para as várias licenciaturas presentes em uma mesma universidade, prioritariamente abordam as práticas de educação inclusiva e seus desdobramentos pedagógicos e secundariamente tratam de aspectos que demandam maior aprofundamento, e que estão retratados nos eixos Sociedade, história e cultura, Conceituação e Legislação e políticas. Aqui não se advoga ou defende a inversão do que foi encontrado, mas se destaca o fato de que as disciplinas para os licenciandos e que tratam a educação das pessoas com deficiência têm como marca certa superficialidade; inclusive essa impressão é reforçada quando se verifica a carga horária reduzida de tais disciplinas (em média 60 horas em cursos que devem abranger 3200 horas).

Sobre a presença, em uma mesma disciplina, dos eixos considerados, observa-se que a incidência de disciplinas com referência aos cinco eixos é da ordem de $5 \%$, seja considerando a quantidade (f1) ou a qualidade (f2), conforme a Tabela 2. A maior parte das disciplinas possuem referências a até três eixos. Entretanto, nota-se que a incidência relativa, conforme as porcentagens, das disciplinas monotemáticas é a maior, considerando ou não as repetições, isto é, em relação tanto à quantidade de disciplinas quanto à qualidade. Tal configuração permite conjecturar sobre a provável ausência de intercomunicação e integração quanto aos conteúdos programados para cada disciplina, ainda que se tenha clareza de que a fixação de conteúdos em planos de aula não expressa a totalidade de possibilidades abertas em sala de aula. Seja como for, insiste-se na pertinência de análises que tomam o currículo prescrito, tendo em vista a preocupação cada vez maior por parte das instituições e dos órgãos centrais (INEP e MEC) com a avaliação interna e externa dos cursos de graduação, com o controle institucional para a garantia da efetivação do que fora programado - as comissões próprias de avaliação das universidades (CPA) também zelam pela realização do que foi programado e estabelecidos nos planos de aula e nas ementas.

Tabela 2 - Frequência (f) de temas/eixos (Sociedade, história e cultura; Conceituações; Legislações e políticas; Práticas de inclusão; Questões pedagógicas) por disciplina relacionada à educação de pessoas com deficiência, com (f1) e sem (f2) das duplicadas

\begin{tabular}{lccccc}
\hline Quantidade de temas & $\mathbf{f 1}$ & $\mathbf{\%}$ & $\mathbf{f 2}$ & $\mathbf{\%}$ & $\begin{array}{c}\neq \\
(\mathbf{1})\end{array}$ \\
\hline Ementas com cinco temas & 23 & 5,3 & 9 & 4,6 & 14 \\
Ementas com quatro temas & 80 & 18,4 & 36 & 18,5 & 44 \\
Ementas com três temas & 100 & 23,0 & 36 & 18,5 & 64 \\
Ementas com dois temas & 109 & 25,1 & 40 & 20,5 & 69 \\
Ementas com tema único & 122 & 28,1 & 74 & 37,9 & 48 \\
Total & $\mathbf{4 3 4}$ & $\mathbf{1 0 0 , 0}$ & $\mathbf{1 9 5}$ & $\mathbf{1 0 0 , 0}$ & $\mathbf{2 3 9}$ \\
\hline
\end{tabular}

(1) Refere-se à diferença entre f1 e f2. Fonte: Simões (2016, p. 101). 
Após sistematização e análise, algumas considerações são destacadas, a seguir, acerca da formação docente. Em primeiro lugar, com base no conteúdo das ementas, identifica-se que o ensino e educação de pessoas com deficiência não constitui preocupação ou prioridade nas licenciaturas das universidades brasileiras, o que foi possível constatar ao se verificar que o eixo Questões pedagógicas, o qual se refere ao trabalho docente em si, obteve menor centralidade dada à temática, ainda que esse mesmo eixo apresente o maior número de disciplinas e a maior incidência de disciplinas monotemáticas, como foi o caso, por exemplo, de disciplinas de estágio supervisionado. Nesse tipo de disciplina, a preocupação com as temáticas da pessoa com deficiência divide espaço com outras; pode-se supor que o estudo da educação das pessoas com deficiências estaria condicionado à presença delas nas salas de aula onde o estágio é realizado, pois há tendência de se valorizar o estudo das situações que advêm da prática observada pelos licenciandos.

Além disso, há uma conduta manifesta nos documentos analisados, e que tem nas disciplinas de ensino de Libras sua mais nítida expressão: uma vez que se destaca a "letra fria da lei" nas ementas e/ou nos planos de aula e que se nomeia uma ou no máximo duas deficiências no projeto pedagógico completo do curso, isso parece eximir da necessidade de tratar as temáticas da pessoa com deficiência de maneira ampla e referida à totalidade social; as temáticas da diversidade (cultural, social, de gênero ou étnico-racial) também recebem o mesmo tratamento: a simples menção a elas parece ser suficiente para supostamente introduzir o futuro professor no universo complexo da escola e da prática docente.

Ainda sobre as disciplinas que tratam de aspectos da educação das pessoas com deficiência, destaque-se a presença de conteúdos hegemônicos nas universidades, embora as disciplinas possam apresentar internamente certa diversidade e variedade. Essa situação pode restringir as variações de abordagens, e isso por ensejar disciplinas monotemáticas. Por outro lado, as disciplinas com menor abrangência de temas parecem permitir maior variabilidade de possíveis abordagens a uma mesma questão. Então, estamos diante de um paradoxo: quanto maior a abrangência de temas, menor a possibilidade de apresentação de outras abordagens; quanto menor for essa abrangência, maior é a possibilidade que as diferentes abordagens sejam contempladas. No entanto, seja em um caso ou no outro, dada a diminuta carga horária consagrada à educação das pessoas com deficiência nos cursos de licenciatura, as chances de que aconteça o aprofundamento teórico, o que demandaria reconhecimento e análise dos problemas envolvidos na Educação Especial na perspectiva da Educação Inclusiva, incluindo a escola, a política, as condições sociais e a estrutura da sociedade capitalista, são mínimas e dependem muito mais da disposição do professor formador do que de uma preocupação genuína presente nos projeto pedagógicos dos cursos. Para esse aprofundamento teórico ocorrer, constituindo importante experiência formativa para os licenciandos, seria fundamental reconhecer as determinações que conformam os conteúdos e as disciplinas, que perpassam exigências não apenas acadêmicas, mas econômicas e sociais. Implicaria, outrossim, não só a identificação e o reconhecimento dos fins da educação nos moldes com que se procede atualmente, mas também a admissão, no plano da consciência, de sua falência no atendimento às necessidades humanas e na desbarbarização da sociedade, como elemento imprescindível à resistência contra a coisificação que sustenta a dominação social e o capitalismo avançado.

\section{Sobre os projetos pedagógicos de curso (PPC)}

Além da análise das disciplinas, algumas considerações a partir dos projetos pedagógicos de curso (PPC) $)^{4}$ que abrigam as disciplinas analisadas são pertinentes. Tal discussão é necessária para a compreensão da perspectiva geral dos cursos sobre as temáticas que envolvem o ensino de pessoas com deficiência. Ainda que tais projetos tenham como referência as diretrizes curriculares já citadas anteriormente, promulgadas no início dos anos 2000, sua análise é procedente, uma vez que, como

4 Como parte da pesquisa realizada por Simões (2016), foi constituída uma amostra representativa da diversidade de cursos de licenciatura ofertados pelas universidades federais, composta por projetos de seis cursos, de diferentes áreas do conhecimento e regiões do País. 
apresentado no início deste artigo, o conteúdo desses projetos sofreu alguma alteração, mas seu teor pouco foi mudado. Tal dinâmica parece se repetir na história da educação brasileira. Saímos da exigência dos currículos mínimos para as "diretrizes", que em tese fazem recomendações e orientam a composição das matrizes curriculares dos cursos. E isso sob a justificativa de ampliar a flexibilidade e liberdade dos cursos para a elaboração de seus próprios projetos.

No entanto, os resultados da investigação de Simões (2016) apontam para o claro compromisso com a adaptação, com a reafirmação do existente, o que impede a autonomia e mantém os indivíduos subsumidos ao poder do mundo administrado, que impõe a integração total de todos, inclusive daqueles que antes eram marginalizados e excluídos, como no caso das pessoas com deficiência e pertencentes às classes baixas. A elaboração predominante apresenta palavras, termos e expressões que, considerados isoladamente, poderiam remeter a um progresso (tais como democracia, inclusão, reconhecimento das diferenças etc.). A partir do texto dos projetos, foram identificados trechos que configuram clara reprodução ipsis litteris do conteúdo das diretrizes curriculares, o que direcionou a atenção para a análise e compreensão de tais trechos, buscando explicitar a relação e o compromisso estabelecidos com o mundo administrado e a reprodução da lógica de submissão, heteronomia e de mercantilização da educação.

Assim, considerando essa reprodução ipsis litteris, identificou-se dois aspectos: de uma parte, em relação aos termos e expressões utilizados/ reproduzidos, sua análise demonstrou como se esvaziaram de sentido real, em razão de sua reprodução; de outra parte, algumas palavras foram adicionadas ao texto reproduzido, o que poderia supor a existência da "[...] possibilidade de questionamento à pseudoformação, à obnubilação de experiências e à ausência de vida nos conteúdos, nos princípios que os definem, enfim, na educação escolar" (SIMÕES, 2016, p. 137).

Entretanto, prevalecem as palavras que perderam o seu significado inicial; ao serem reproduzidas indiscriminadamente indicam que a percepção de sua recorrência não é nítida na consciência dos indivíduos, posto que sempre se faz referência a elas, porém pouco se detém na compreensão, definição ou problematização de seus significados. Tanto nas diretrizes quanto nos projetos - esses últimos já reproduções das diretrizes do curso a que se referiam -, um conjunto de expressões foram analisadas, não sendo possível determinar claramente a que se referem. Tais expressões compõem uma espécie de recurso de linguagem limitante e submetido à lógica vigente, que é a manifestação da ausência de consciência ou de sua coisificação. Tais recursos pressupõem que tudo já está subentendido pelo leitor, baseado em seu suposto conhecimento prévio e naquilo que fica, segundo a expressão popular, "dito pelo não dito". O conteúdo total dos documentos, analisados dentro de seu contexto e organização própria, compõe-se de uma série de referências e argumentos que não estão plenamente explicadas ou explicitadas nos próprios documentos. Todavia, tal conhecimento prévio é arbitrário, espacial e historicamente constituído, e não universal e anacronicamente compreendido, como fica implicitamente evidente nos documentos.

\section{As diretrizes para a formação de professores}

Ante o exposto, a educação escolar e a formação docente passaram a ser encaradas não mais como práticas sociais com conteúdo político importante, necessário e fundamental, mas como técnicas sociais, entendidas estas como método capaz de provocar mudanças de comportamento e atitudes. No fundo prevalece a intenção de que sejam produzidas condições subjetivas para a adaptação à sociedade. A educação é concebida como prática que deve promover situações que levem a tais mudanças. Esse entendimento não é algo novo e um autor interessado nos vínculos entre educação e sociedade, nas décadas de 1940 e 1950, já apontava nessa direção. Dessa perspectiva, a educação deveria ser planejada "[...] de modo que se integre [cada indivíduo] nos padrões vigentes de interação e organização social" (MANNHEIM, 1987, p. 325). $\mathrm{Na}$ proposta para os cursos de formação inicial de professores em análise parece predominar a tendência que os transforma em instrumentos de adaptação das novas gerações aos padrões sociais marcadamente vinculados à lógica da dominação. 
Torna-se oportuno relembrar autores da sociologia funcionalista, como Karl Mannheim, porque apesar das várias críticas (necessárias e justas) formuladas a essa posição teórica, verifica-se que apontamentos feitos há mais de 65 anos - e já superados - continuam presentes no pensamento educacional. A premissa básica que aparentemente deve orientar os cursos de formação é a seguinte: “[...] as pessoas têm de ser condicionadas e educadas para se integrarem nos padrões vigentes de vida social" (MANNHEIM, 1987, p. 325). Sabemos o que isso significa: mais importante que a formação para a autonomia é a adaptação à sociedade burguesa e à divisão social do trabalho ensejada por ela.

A educação reduzida à técnica social expressa toda a dificuldade de romper com o que Adorno (1995b, p. 132) denomina de consciência coisificada, que "[...] é sobretudo uma consciência que se defende em relação a qualquer vir-a-ser, frente a qualquer apreensão do próprio condicionamento, impondo como absoluto o que existe de um determinado modo". Essa forma de consciência condiciona a relação com a técnica. Nas palavras do autor:

Os homens inclinam-se a considerar a técnica como [...] uma força própria, esquecendo que ela é a extensão do braço dos homens. Os meios - e a técnica é um conceito de meios dirigidos à autopreservação da espécie humana - são fetichizados, porque os fins - uma vida humana digna - encontram-se encobertos e desconectados da consciência das pessoas. (ADORNO, 1995b, p. 132-133).

Não resta dúvida quanto à existência de variáveis e condições objetivas (de ordem política, econômica, social e cultural) que determinam e muitas vezes se tornam obstáculos ao trabalho do professor. Portanto, sua formação não pode prescindir de situar em que tipo de sociedade e quais problemas os seus membros enfrentam, seja na escola ou fora dela. No entanto, o aumento das atribuições conferidas ao professor, observado nas diretrizes em análise, cujas habilidades precisam ser desenvolvidas muito precocemente (na formação inicial), pode tirar o foco do que é talvez a principal razão de ser de sua atividade: o ensino de conteúdos (ligados ou não diretamente à disciplina para a qual o docente está preparado) de modo que seus alunos tenham totais e plenas condições de aprender e se apropriar do que foi ensinado.

Seja como for, aquilo que o professor poderia aprender com sua experiência - por exemplo, depois de alguns anos atuando na mesma escola, junto com seus colegas, poder propor soluções para os problemas de indisciplina ou provenientes da relação com a comunidade - é cobrado dele já no início do exercício do magistério e, consequentemente, do curso de formação inicial. Que fique claro: não se está advogando em favor da formação continuada ou em serviço, em contraposição à inicial, mas enfatizando que o curso de formação inicial não tem potencial para preencher todas as lacunas reconhecidas e projetadas nas licenciaturas, embora todas elas estejam localizadas no próprio campo da educação. Em certa medida, por se responsabilizar o professor pelo fracasso da escola pública e se cobrar dele que assuma o compromisso pela reversão desse quadro, os profissionais que atuam como formadores (nos cursos de licenciatura) também recebem parte dessa responsabilidade.

É evidente que os cursos de formação inicial de professores merecem grande parte das críticas que recebem, principalmente aquelas que apontam para a superficialidade e incoerência de seus projetos de curso e para a pouca consistência teórica, decorrendo disso o fato de que as próprias disputas e embates da área educacional não são desenvolvidos e aprofundados. E as diretrizes, nesse sentido, constituem uma tentativa de por em evidência as situações e contextos que cercam o exercício do magistério. Como se poderá observar adiante, isso é feito transformando tais situações e contextos em temas e conteúdos disciplinares. Insiste-se, a inclusão de tudo isso no currículo de formação de professores é importante, mas algo parece se perder e as consequências não poderiam ser outras: pouca consistência teórica, uma vez que as disciplinas e atividades ligadas aos chamados fundamentos da educação têm carga horária sempre insuficiente; mais uma vez, insiste-se: o foco tende a recair na formação técnica, dimensão necessária, mas não suficiente para a docência. E um indicador dessa realidade é a constante presença nas políticas educacionais de propostas de formação continuada e em serviço. Mais adiante voltaremos a este ponto. 
Antes de prosseguir, considera-se necessário apresentar algumas referências para contribuir com o debate sobre a formação docente. Considera-se fundamental fixá-la em termos de formação intelectual do professor, que Adorno (1995a, p. 54) definiu nos seguintes termos, quando analisava o processo de habilitação de professores, na Alemanha dos anos 1960: os futuros professores devem ser capazes de "[...] ir além do seu aprendizado estrito, na medida em que desenvolvem uma reflexão acerca de sua profissão, ou seja, pensam acerca do que fazem, e também refletem acerca de si mesmos". Assim, os impasses e ambiguidades dos cursos de formação de professores só poderão ser superados se seus profissionais forem capazes de refletir sobre os limites (não somente as possibilidades) de sua prática e sobre a situação objetiva da própria profissão.

A partir deste ponto são tecidas considerações com o fito de analisar as Diretrizes Curriculares Nacionais para a Formação Inicial e Continuada dos Profissionais do Magistério da Educação Básica, parte integrante do parecer $\mathrm{CNE} / \mathrm{CP} \mathrm{n}^{\circ}$ 02/2015, emitido pelo Conselho Nacional de Educação. O relator do processo e das diretrizes indica a necessidade de conferir "organicidade" tanto ao trabalho pedagógico como à formação de professores, partes integrantes do projeto nacional de educação:

A consolidação das normas nacionais para a formação de profissionais do magistério para a educação básica é indispensável para o projeto nacional da educação brasileira, em seus níveis e suas modalidades da educação básica, tendo em vista a abrangência e a complexidade da educação de modo geral e, em especial, a educação escolar inscrita na sociedade. (BRASIL, 2015, p. 21).

São destacados alguns princípios que necessitariam ser estabelecidos no campo educacional. Destes derivam dois compromissos: a) público, para garantir o direito à educação de qualidade, esta última assentada em bases científicas e técnicas; b) político, para consolidar a soberania nacional e desenvolver uma nação democrática, justa, inclusiva e que proporcione a emancipação e a valorização da diversidade.

Já nesse preâmbulo observa-se a incorporação de uma série de temas introduzidos no debate educacional nos últimos anos, o que denota uma característica presente na formulação de outros documentos oficiais da área da educação: a tendência de incluir tudo o que está em disputa e todos os interesses dos grupos representados no debate. Se, por um lado, isso expressa o processo de negociação envolvido, por outro, pode tornar-se um obstáculo à fixação de objetivos e prioridades fundamentais e à focalização no que realmente importa. Aliás, parece ser exatamente o que acontece, pois é difícil identificar o básico e principal na política de formação de professores - tome-se como exemplo a ênfase conferida à formação inicial e continuada, fato já assinalado.

Ambos os momentos são tratados de modo articulado e recebem o mesmo destaque. Observe-se como é justificada a formulação das diretrizes: devem ser definidas "[...] diretrizes conjuntas para a formação inicial e continuada dos profissionais do magistério da educação básica, bem como as políticas voltadas para maior organicidade desta formação" (BRASIL, 2015, p. 21). Chama atenção o fato de a formação de professores ser compreendida exatamente como um processo que deve continuar após o término do curso da formação inicial. Sem dúvida, proporcionar condições para que os professores possam continuar a estudar e aprender, enfim, a aperfeiçoar sua prática e a ação educativa que desenvolvem é fundamental. Entretanto, se não ficar evidente nas políticas voltadas para a formação e profissionalização docente que a licenciatura é momento crucial, pois pode conduzir à consistência teórica e à apropriação das técnicas e conhecimentos necessários para o exercício qualificado da educação das novas gerações, então temos uma situação em que a formação continuada também perde seu potencial, uma vez que passa a ser concebida unicamente como momento de sanar os problemas que o professor enfrentou e não resolveu no curso de formação inicial.

Valoriza-se aqui esse primeiro momento da formação profissional, que deve ocorrer na universidade ou no ensino superior, porque esta deve estar integrada e articulada com a formação geral e intelectual. A licenciatura pode se constituir em ocasião para que o futuro professor consiga romper com as relações sociais que o produziram até então: "o indivíduo só se emancipa quando se 
liberta do imediatismo de relações que de maneira alguma são naturais [...]" (ADORNO, 1995a, p. 67); e a formação profissional é a oportunidade de os licenciandos "[...] tomarem consciência das dificuldades, da ruptura entre sua existência e sua profissão - e essa consciência deverá inevitavelmente ocorrer na universidade" (ADORNO, 1995a, p. 68). Reconhecendo que as principais dimensões e aspectos são contemplados nas diretrizes para a formação dos professores, com temas sociais e educacionais importantes sendo tratados, como a diversidade cultural, os direitos humanos, a educação inclusiva e o meio ambiente, ainda assim conteúdos e experiências relacionados à educação política (ADORNO, 1995b) dos futuros professores poderiam ser definidos e explicitados de forma mais precisa e contundente.

Nas diretrizes é proposto e defendido que os projetos das licenciaturas devem contemplar a articulação entre teoria e prática, a indissociabilidade ensino, pesquisa e extensão, o que proporcionaria uma "sólida base teórica e interdisciplinar", tornando seus egressos "agentes formativos da cultura" (BRASIL, 2015, p. 23). Se considerarmos que tudo isso é alcançado por meio de uma matriz curricular na qual estão incluídos conteúdos os mais diversificados, ainda que todos de fato digam respeito à educação, pode-se concluir que são os próprios estudantes os responsáveis por articular sua experiência no ensino superior. Destaque-se o seguinte excerto das diretrizes:

Os cursos de formação deverão garantir nos currículos conteúdos específicos da respectiva área de conhecimento ou interdisciplinares, seus fundamentos e metodologias, bem como conteúdos relacionados aos fundamentos da educação, formação na área de políticas públicas e gestão da educação, seus fundamentos e metodologias, direitos humanos, diversidades étnico-racial, de gênero, sexual, religiosa, de faixa geracional, Língua Brasileira de Sinais (Libras), educação especial e direitos educacionais de adolescentes e jovens em cumprimento de medidas socioeducativas. (BRASIL, 2015, p. 51).

Esses e outros conteúdos devem ser oferecidos tendo em vista a seguinte estrutura de curso:

a) 400 horas de prática como componente curricular $[\ldots]$; b) 400 horas dedicadas ao estágio supervisionado, na área de formação e atuação na educação básica, contemplando também outras áreas específicas [...];

c) pelo menos 2.200 horas dedicadas às atividades formativas $[\ldots]$;

d) 200 horas de atividades teórico-práticas de aprofundamento em áreas específicas de interesse dos estudantes [...] por meio da iniciação científica, da iniciação à docência, da extensão e da monitoria, entre outras [...] (BRASIL, 2015, p. 30).

Por fim, cabe destacar que as 3.200 horas previstas devem ser distribuídas pelos seguintes núcleos:

I - núcleo de estudos de formação geral, das áreas específicas e interdisciplinares, e do campo educacional, seus fundamentos e metodologias, e das diversas realidades educacionais [...];

II - núcleo de aprofundamento e diversificação de estudos das áreas de atuação profissional, incluindo os conteúdos específicos e pedagógicos e a pesquisa priorizada pelo projeto pedagógico das instituições;

III - núcleo de estudos integradores para enriquecimento curricular [...] (BRASIL, 2015, p. 29).

Com toda essa organização complexa recomendada, nada é afirmado sobre como será efetivada a tão almejada integração e articulação de conhecimentos práticos e teóricos. Em outras palavras, a não ser a menção ao caráter interdisciplinar a reger o funcionamento das atividades dos cursos, a tarefa de atribuir significado - político, social e educacional - para o aprendizado é menos dos professores formadores e mais do aluno.

De outra parte, imagina-se que todo o conteúdo indicado somente poderá compor de fato a matriz curricular dos cursos se a eles forem dedicados apenas o tempo mínimo necessário (um semestre ou entre 30 e 45 horas de aulas), o que dificultará o aprofundamento dos estudos e a consolidação dos conhecimentos adquiridos. Não se trata de se posicionar contrariamente à incorporação, pelos cursos de formação de professores, de temas fundamentais e sobre os quais incidem a prática pedagógica, mas de chamar atenção para o fato de que a reflexão sobre as condições objetivas existentes nas universidades, e em outras instituições de ensino superior, e que dificultariam (ou facilitariam) a realização dessas diretrizes, não é proposta nem considerada. 
De certo modo, esse modelo de formação de professores está relacionado com a concepção expressa nas diretrizes para os cursos de licenciatura:

Compreende-se a docência como ação educativa e como processo pedagógico intencional e metódico, envolvendo conhecimentos específicos, interdisciplinares e pedagógicos, conceitos, princípios e objetivos da formação que se desenvolvem na construção e apropriação dos valores éticos, linguísticos, estéticos e políticos do conhecimento inerentes à sólida formação científica e cultural do ensinar/aprender, à socialização e construção de conhecimentos e sua inovação, em diálogo constante entre diferentes visões de mundo. (BRASIL, 2015, p. 42).

A compreensão sobre o que é o magistério e sobre como deve ser a formação docente aponta para a ampliação das tarefas e obrigações que recaem sobre os professores. Mais do que transmitir determinados conhecimentos e valores é necessário abarcar todo um conjunto de situações, que assimiladas por seus alunos, possibilitaria a eles a inserção exitosa na vida social, o que inclui aspectos ligados ao exercício da cidadania, ao mundo do trabalho e às constantes inovações proporcionadas pelo avanço das forças produtivas expressas no desenvolvimento das tecnologias da informação e da comunicação, além dos tópicos acerca do exercício da cidadania, do respeito à diversidade cultural, da preservação do meio ambiente, da inclusão social das pessoas com deficiência, do reconhecimento das minorias etc.

Por isso, os documentos que estabelecem as diretrizes para a formação de professores precisam ser amplos, justamente para dar conta de todos os aspectos relacionados à educação das novas gerações. Contudo, ao serem assim, por ampliarem as atribuições do professor da educação básica, acentuam os impasses e indefinições que têm cercado o debate sobre formação inicial e continuada de professores. De fato, tais diretrizes parecem abarcar o que é importante, mas, por isso mesmo, estimulam que tudo seja tratado de forma superficial. No já referido estudo realizado sobre os projetos pedagógicos de cursos de licenciaturas de universidades federais brasileiras, com foco no modo como são introduzidos os conteúdos concernentes à educação das pessoas com deficiência, Simões (2016), um dos autores deste artigo, assinala que os futuros professores não são preparados para lidar com os alunos e suas singularidades, evidenciando uma tendência que leva ao abreviamento dos estudos propostos e ao esvaziamento dos significados de conceitos e termos que expressariam as contradições e toda a complexidade da vida social e da educação escolar.

Ainda sobre a ampla gama de atividades envolvidas na docência, as funções designadas às escolas e à educação em geral tornam a prática dos professores muito fluída, com sua energia sendo diluída em várias frentes de trabalho. Insiste-se, não se defende que os professores devam "virar as costas" para a realidade social que afeta decisivamente a vida de seus alunos, mas parece essencial desenvolver um debate que tenha como meta demarcar claramente o que diz respeito à educação escolar. A esse propósito, recorre-se às formulações de Adorno (1998, p. 77):

Una escuela abierta por completo hacia fuera, sin trabas ni inhibiciones, perdería posiblemente también lo que en ella hay de acogedor y formativo. [...] Dado, por otra parte, que quienes se mueven en el ámbito escolar no admiten la menor intromisión en su territorio, está claro que la tendencia de éstes a cerrarse en sí mismo tiende a acentuarse, al menos frente a la crítica. [...] Habría que hacer comprender que la escuela no es un fin en sí misma, que su carácter cerrado es una necesidad, no la virtud [...]

Considera-se que a já referida ampliação das tarefas do professor leva a uma abertura ao exterior que coloca em xeque a especificidade de sua atividade profissional. Assim, tem-se a impressão de que o ensino propriamente dito é cada vez mais desprestigiado na prática pedagógica. A diversificação do espectro de atuação, em atendimento às demandas sociais externamente estabelecidas, enseja a definição do magistério nos seguintes termos, entre tantas possibilidades: "aplicação ao campo da educação de contribuições e conhecimentos, como o pedagógico, o filosófico, o histórico, o antropológico, o ambiental-ecológico, o psicológico, o linguístico, o sociológico, o político, o econômico, o cultural" (BRASIL, 2015, p. 50). Ainda que necessária, a ampliação verificada é de tal magnitude que a prática docente perde sua singularidade e a referência historicamente 
constituída que confere identidade à profissão do magistério. Mais uma vez, essa situação parece agravar os impasses presentes nas políticas e propostas de formação do professor.

De certo modo, as diretrizes para os cursos de licenciatura são determinadas pelas incertezas que perpassam a docência na atualidade. O professor precisa ter conhecimentos e possuir destrezas que o habilite a ensinar seus alunos, precisa ser um gestor educacional, precisa ser um especialista nas ciências da educação, precisa também agir sobre os aspectos socioculturais que estão presentes na realidade da escola e que interferem em seu trabalho. E ele só pode dar conta de tudo isso se abrir mão da formação profissional propriamente dita e colocar em prática os parcos conhecimentos adquiridos de cada âmbito, atuando muito mais de modo técnico do que pedagógico e político. Talvez cursos mais bem dimensionados garantissem especificidade e uma formação que subordinasse a técnica (compreendida como meio) às finalidades sociais e democráticas da educação.

\section{REFERÊNCIAS}

ADORNO, Theodor W. A Filosofia e os professores. In: Terra, 1995a. p. 51-74.

Educação e emancipação. São Paulo: Paz e . Educação após Auschwitz. In: . Educação e emancipação. São Paulo: Paz e Terra, 1995b. p. 119-138. . Tabúes sobre la profesión de enseñar. In: Educación para la emancipación. Madrid: Ediciones Morata, 1998. p. 65-78.

BRASIL. Ministério da Educação. Conselho Nacional de Educação. Parecer CNE/CP no 2, de 09 de junho de 2015. Diretrizes Curriculares Nacionais para a Formação Inicial e Continuada dos Profissionais do Magistério da Educação Básica. Brasília, DF, 2015. Disponível em: <http://pronacampo.mec.gov.br/images/pdf/parecer_cne_ cp_2_2015_aprovado_9_junho_2015.pdf $>$. Acesso em: 01 out. 2017.

FREITAS, Luiz Carlos de. A avaliação e as reformas dos anos de 1990: novas formas de exclusão, velhas formas de subordinação. Educação e Sociedade, Campinas, SP, v. 25, n. 86, p. 133-170, 2004.

MANNHEIM, Karl. A crise da sociedade contemporânea. In: PEREIRA, Luiz; FORACCHI, Marialice M. Educação e sociedade. São Paulo: Nacional, 1987. p. 321-342.

MORAES, Reginaldo C. Reformas neoliberais e políticas públicas: hegemonia ideológica e redefinição das relações Estado-sociedade. Educação e Sociedade, Campinas, SP, v. 23, n. 80, p. 13-24, 2002.

SADER, Emir; GENTILI, Pablo. Pós-neoliberalismo: as políticas sociais e o Estado democrático. Rio de Janeiro: Paz e Terra, 1995.

SANTOMÉ, Jurgo Torres. A educação em tempos de neoliberalismo. Porto Alegre: Artmed, 2003.

SIMÕES, Maria Cristina Dancham. Formação do indivíduo, formação docente e educação especial: o lugar do sujeito e o compromisso com a adaptação. 2016. Tese (Doutorado em Educação) - Pontifícia Universidade Católica de São Paulo (PUC/SP), São Paulo, 2016.

STROMQUIST, Nelly P. Educação latino-americana em tempos globalizados. Sociologias, Porto Alegre, v. 14, n. 29, p. 72-99, 2012.

Recebido: $15 / 10 / 2017$

Aprovado: 06/11/2017 